\title{
Cusp observations during a sequence of fast IMF $B_{Z}$ reversals
}

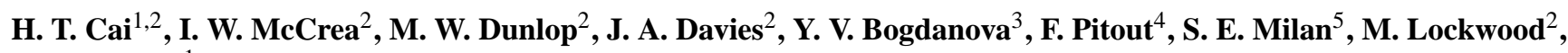 \\ and S. Y. Ma ${ }^{1}$ \\ ${ }^{1}$ School of Electronic Information, Wuhan University, 430079, China \\ ${ }^{2}$ Space Science and Technology Department, Rutherford Appleton Laboratory, Chilton, OX11 0QX, UK \\ ${ }^{3}$ Department of Physics, La Trobe University, Melbourne, Victoria, 3086, Australia \\ ${ }^{4}$ Max-Planck-Institut für Extraterrestrische Physik, Garching, Germany \\ ${ }^{5}$ Department of Physics and Astronomy, University of Leicester, Leicester, UK
}

Received: 24 October 2008 - Revised: 11 May 2009 - Accepted: 26 June 2009 - Published: 9 July 2009

\begin{abstract}
In recent years, a large number of papers have reported the response of the cusp to solar wind variations under conditions of northward or southward Interplanetary Magnetic Field (IMF) Z-component $\left(B_{Z}\right)$. These studies have shown the importance of both temporal and spatial factors in determining the extent and morphology of the cusp and the changes in its location, connected to variations in the reconnection geometry. Here we present a comparative study of the cusp, focusing on an interval characterised by a series of rapid reversals in the $B_{Z}$-dominated IMF, based on observations from space-borne and ground-based instrumentation. During this interval, from 08:00 to 12:00 UT on 12 February 2003, the IMF $B_{Z}$ component underwent four reversals, remaining for around $30 \mathrm{~min}$ in each orientation. The Cluster spacecraft were, at the time, on an outbound trajectory through the Northern Hemisphere magnetosphere, whilst the mainland VHF and Svalbard (ESR) radars of the EISCAT facility were operating in support of the Cluster mission. Both Cluster and the EISCAT were, on occasion during the interval, observing the cusp region. The series of IMF reversals resulted in a sequence of poleward and equatorward motions of the cusp; consequently Cluster crossed the highaltitude cusp twice before finally exiting the dayside magnetopause, both times under conditions of northward IMF $B_{Z}$. The first magnetospheric cusp encounter, by all four Cluster spacecraft, showed reverse ion dispersion typical of lobe reconnection; subsequently, Cluster spacecraft 1 and 3 (only) crossed the cusp for a second time. We suggest that, during this second cusp crossing, these two spacecraft were likely to have been on newly closed field lines, which were first reconnected (opened) at low latitudes and later reconnected again (re-closed) poleward of the northern cusp.
\end{abstract}

Correspondence to: H. T. Cai

(htcai@whu.edu.cn)
At ionospheric altitudes, the latitudinal excursions of the cusp/cleft region in response to the series of the IMF polarity changes were clearly captured by both the ESR and the Pykkvibaer radar of the SuperDARN HF network. The Open-Closed field-line Boundary (OCB) inferred from the HF radar observations underwent latitudinal variations in response to the IMF polarity changes that are in accordance with those predicted by Newell et al. (1989). Furthermore, variations in the ionospheric parameters yielded by the EISCAT VHF and ESR radars are basically consistent with inferences drawn from the HF radar observations. We conclude that Cluster spacecraft 1 and 3 crossed the cusp for a second time as a result of the latitudinal migration of the cusp in response to the IMF polarity reversals; at that time, however, the cusp lay poleward of spacecraft 4 . Snapshots of the cusp from two DMSP satellite passes provide further support for this interpretation.

Keywords. Ionosphere (Polar ionosphere) - Magnetospheric physics (Magnetopause, cusp, and boundary layers; Plasma convection)

\section{Introduction}

The cusp is commonly regarded as that region of the magnetospheric cavity where solar wind plasma has direct access to the upper atmosphere. It is widely accepted that cusp dynamics are highly influenced by the nature of the interaction of the solar wind with the magnetosphere, especially in terms of reconnection between the Interplanetary Magnetic Field (IMF) and the geomagnetic field. Both observations and theoretical modelling indicate that the site of magnetic reconnection is principally determined by the polarity of the IMF. Generally, reconnection on the dayside occurs in the vicinity of the sub-solar magnetopause under southward

Published by Copernicus Publications on behalf of the European Geosciences Union. 
IMF conditions, whereas for steadily northward IMF, reconnection can take place between the IMF and the field lines of the tail lobe (Dungey, 1963; Russell et al., 1972; Burch et al., 1980; Reiff et al., 1980; Cowley et al., 1981, 1983; Lockwood et al., 1999; Milan et al., 2000). Low-latitude reconnection (hereafter used to refer to reconnection near the sub-solar magnetopause) during southward IMF differs from the lobe reconnection for northward IMF mainly in the fact that, as discussed by Lockwood and Moen (1999), the former generates open flux, whereas the latter reconfigures flux which is already open. Recent work, however, reveals the actual situation to be far more complex than this idealistic description would suggest. Low-latitude reconnection can sometimes continue after the IMF has turned northward (e.g. Freeman et al., 1993; Onsager et al., 1994; Scurry et al., 1994a, b; Phan et al., 1996; Fuselier et al., 1997; Chandler et al., 1999). Moreover, lobe reconnection may also take place for some time after the IMF has turned southward (McCrea et al., 2000). Low-latitude and lobe reconnection have been reported to occur simultaneously under $B_{Y}$-dominated IMF conditions (Wing et al., 2001), and during intervals of variable IMF $B_{Z}$ (Pitout et al., 2002). Dual lobe reconnection, identified by either distinctive auroral and ionospheric convection signatures (Imber et al., 2007) or from satellite observations (Bogdanova et al., 2005), has been observed during periods of steadily northward IMF.

The cusp exhibits characteristic features depending on the location of the reconnection site. Under southward IMF conditions, the cusp ion flux exhibits "typical" energy dispersion, in that its peak energy decreases with increasing latitude; this is generally interpreted as evidence of magnetosheath plasma entry following reconnection. Field lines, newly opened at low latitudes, are swept poleward with the magnetosheath flow, driving anti-sunward high-latitude ionospheric plasma convection. Transient ionospheric signatures of low-latitude reconnection during southward IMF are observed to move poleward in the cusp/cleft region, entrained in the anti-sunward flow (Lockwood et al., 1998). Under steadily northward IMF conditions, "reverse" ion dispersion signatures are observed in the cusp (Burch et al., 1980; Reiff et al., 1980; Woch et al., 1992); these are understood in terms of the expected lobe reconnection, occurring poleward of the cusp. In such a scenario, the plasma convection in the cusp is sunward, as discussed by Phan et al. (2005). Maezawa et al. (1976) provided the first observational evidence of such sunward flow in the polar cap during lobe reconnection, using ground-magnetometer observations. Milan et al. (2000) have since presented SuperDARN HF radar observations of sunward convection in the cusp/cleft region under northward IMF conditions.

The latitudinal position of the cusp is reported to vary with the orientation of the IMF. Statistical work (e.g. Newell et al., 1989; Pitout et al., 2006) suggests that the effect of the IMF $B_{Z}$ component on the cusp's latitudinal location outweighs that of the other two components. A plausible explanation for this is magnetic reconnection; the $\mathrm{Z}$ component of the IMF controls the site on the magnetopause where magnetic reconnection takes place, and thus directly affects the latitudinal location of the cusp. This hypothesis also provides an explanation for the fact that the cusp generally lies further equatorward when the IMF $B_{Z}$ component is negative, and that it moves back and forth in latitude when the IMF $B_{Z}$ component changes its orientation. McCrea et al. (2000) reported a case in which the cusp was observed to move equatorward in response to a southward turning of the IMF $B_{Z}$ component, whilst poleward motion of cusp has been observed in the case of a northward turning (Pitout et al., 2001). How the cusp reacts to changes of the IMF from southward to northward, or vice versa, is currently a topic of great interest (Bogdanova et al., 2007; Hu et al., 2008; Escoubet et al., 2008). Additionally, "triple" cusp crossings, observed by Cluster have been reported, and explained in terms of the motion of a single cusp due to either changes in the azimuthal component of the solar wind (Zong et al., 2004) or oscillations of the magnetosphere (Zong et al., 2008).

While cusp behaviour during southward IMF conditions has been extensively reported, there has recently been increased interest in the cusp under northward IMF (Maynard et al., 2000; Pryse et al., 2000a, b, c; Pitout et al., 2001; Lavraud et al., 2002, 2004; Bogdanova et al., 2005; Hu et al., 2008), particularly in case studies which combine spacecraft and ground-based facilities. In the present paper, satellite observations are combined with ground-based radar measurements during an interval characterised by multiple rapid IMF $B_{Z}$ reversals, in a bid to investigate IMF $B_{Z}$ control of the cusp.

\section{Observations}

During the interval extending from 08:00 to 12:00 UT on 12 February 2003, Cluster was flying sunwards from the magnetotail, towards apogee on the dayside; the Cluster spacecraft 4 (SC4) was leading the tetrahedral configuration whilst spacecraft 3 (SC3) lagged behind at distance of about $6000 \mathrm{~km}$, as shown in Fig. 1. The radars of the EISCAT facility were operating in support of Cluster, in their so-called Cluster-mode. In this mode, the steerable ESR $32 \mathrm{~m}$ radar and the EISCAT mainland VHF radar, located at Troms $\varnothing$, were both directed poleward at low elevation $\left(30^{\circ}\right)$ with azimuths of $-24^{\circ}$ and $-0.5^{\circ}$, respectively. Note that the $42 \mathrm{~m}$ dish of the EISCAT Svalbard Radar (ESR) at Longyearbyen is fixed such that it points permanently in the field-aligned direction. The configuration of the EISCAT radars is shown in Fig. 2, on which the magnetic ground track of Cluster, mapped along the field lines of the Tsyganenko 96 model (Tsyganenko, 1995) is also marked at 30-min intervals starting at 08:00 UT. The spacecraft map to a location slightly poleward of Longyearbyen, and their footprints are predicted to intersect with the ESR $32 \mathrm{~m}$ radar beam at around 


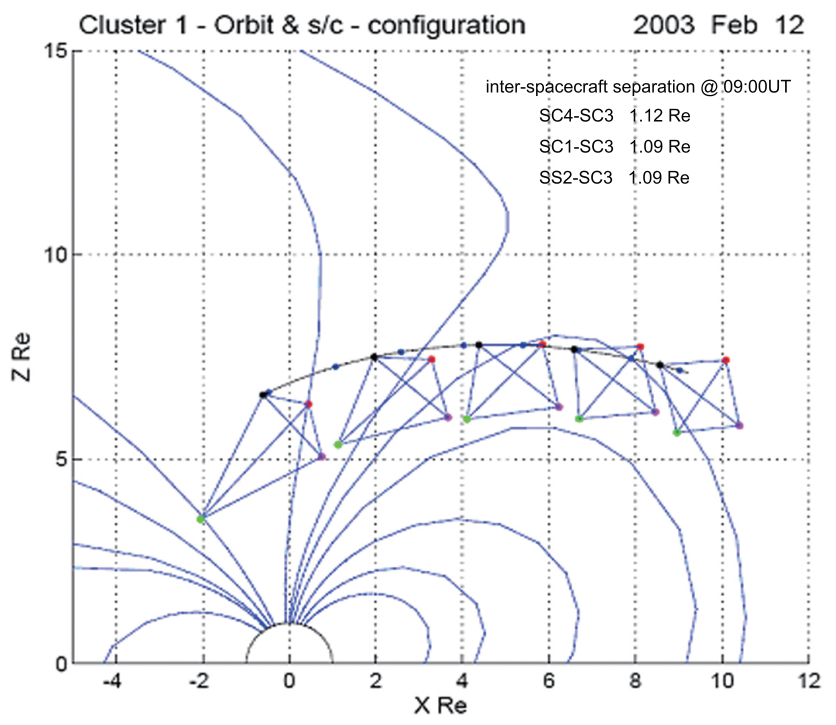

Fig. 1. Illustration of the Cluster orbit in the $X-Z$ plane of the GSE coordinate system during the interval extending from 08:00 to 12:00 UT on 12 February 2003. The 4-spacecraft configuration is also shown in the figure, with the inter-spacecraft distances multiplied by a factor of 3 for clarity (SC1: black; SC2: red; SC3: green and SC4: magenta). The magnetospheric field lines are also displayed for guidance.

11:00 UT. Overpasses of two of spacecraft of the DMSP fleet, F13 and F14, are also displayed in Fig. 2, as red and green lines respectively. The trajectory of DMSP F13 during the interval 09:50 to 09:54 UT and that of F14 from 09:28 to 09:30 UT are highlighted as thick line segments, these being the times at which the spacecraft map to locations close to Svalbard. Black arrows indicate the directions of flight of Cluster and the DMSP spacecraft.

\subsection{Solar wind and IMF observations}

Figure 3 presents solar wind and IMF observations from both ACE (in red) and Wind (in blue) from 08:00 until 12:00 UT on 12 February 2003, which are lagged to the nose of the bow shock (obtained from NASA OMNIWeb). Solar wind dynamic pressure is presented in the uppermost panel (a). The three components of the IMF, in GSM coordinates, are shown in panels (b) to (d). The lower panel (e) presents the IMF clock angle, $\theta$, defined as (Pryse et al., 2006),

$\theta=\tan ^{-1}\left(\left|B_{Y} / B_{Z}\right|\right)\left(B_{Z}>0\right)$

$\theta=180^{\circ}-\tan ^{-1}\left(\left|B_{Y} / B_{Z}\right|\right)\left(B_{Z}<0\right)$

$\theta$ values less than $90^{\circ}$ represent positive $B_{Z}$ and $\theta$ greater than $90^{\circ}$ denotes southward IMF. The reader should remember that an additional time shift, relative to the calculated solar wind transit time, must be added in order to obtain the time at which these solar wind effects are experienced in the

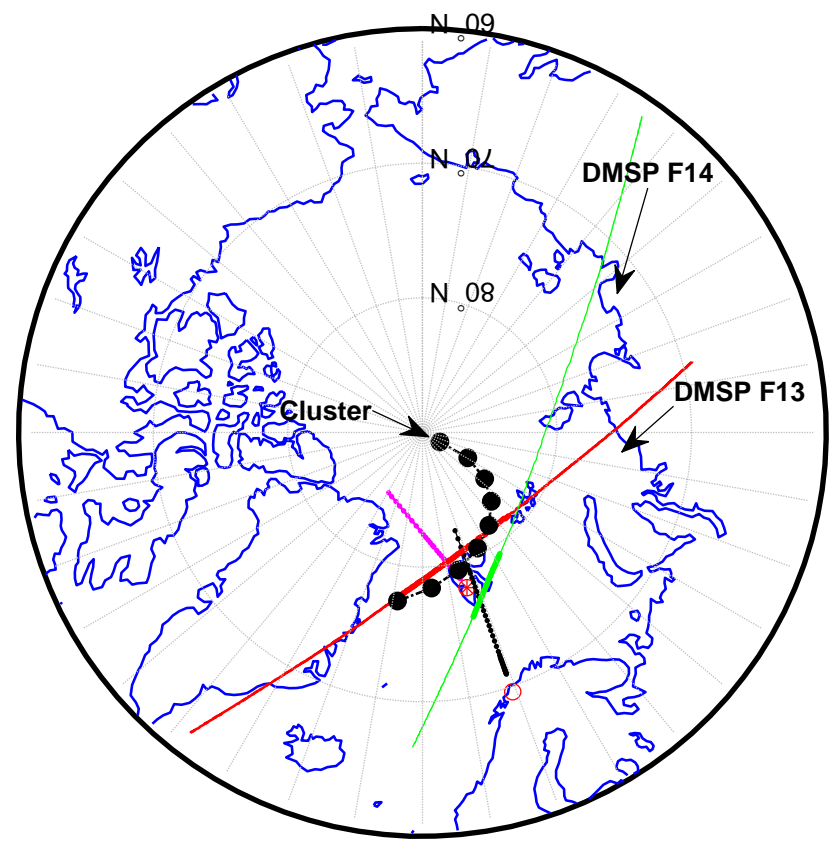

Fig. 2. Geometric configuration of Cluster, DMSP and the EISCAT radars on 12 February 2003. The footprint of Cluster SC1, predicted by the T96 model between 08:00 and 12:00 UT, is plotted at 30-min time intervals as a black dot. Overpasses of DMSP F13 and F14 are also displayed in the figure as red and green lines, respectively. The trajectory of F13 between 09:50 and 09:54 UT, and that of F14 from 09:28 to 09:30 UT, are highlighted by thick red and thick green line segments. Black arrows indicate the direction of travel of the Cluster and DMSP spacecrafts. The ESR $32 \mathrm{~m}$ and EISCAT Troms $\emptyset$ VHF radar beams are plotted using magenta and black solid lines, respectively. The ESR radar location is marked by a red asterisk, and the site of the EISCAT Troms $\varnothing$ VHF radar as a red circle.

magnetosphere and ionosphere. This additional delay is to allow for the propagation of solar wind effects across the magnetosheath - we use a value of four minutes, based on the work of Khan and Cowley (1999) - and the effective Alfvén travel time from the magnetopause to the ionosphere - a further two minutes, (Khan et al., 1999). These delays actually depend on factors such as IMF $B_{Y}$ and $B_{X}$ orientation and, in reality, any predictions for the timings of IMF effects in the magnetosphere and ionosphere are only likely to be accurate to within about five minutes. In the following discussion, we adopt the convention that the timings given for changes in the IMF are those at the nose of the bow shock, and point out where additional delays should be added to compare with the responses seen by Cluster and the ground-based radars.

The solar wind and IMF components from the Wind and ACE spacecraft, shown in Fig. 3, are basically consistent with each other. During this interval, ACE was located at around $(222.5,-40,9.1) R_{E}$, whilst Wind was around $(195.6,-4.9,-15.2) R_{E}$. Thus solar wind observations from Wind are employed in the present study, due to its shorter distance to the Earth and closer location to the Sun-Earth line. 

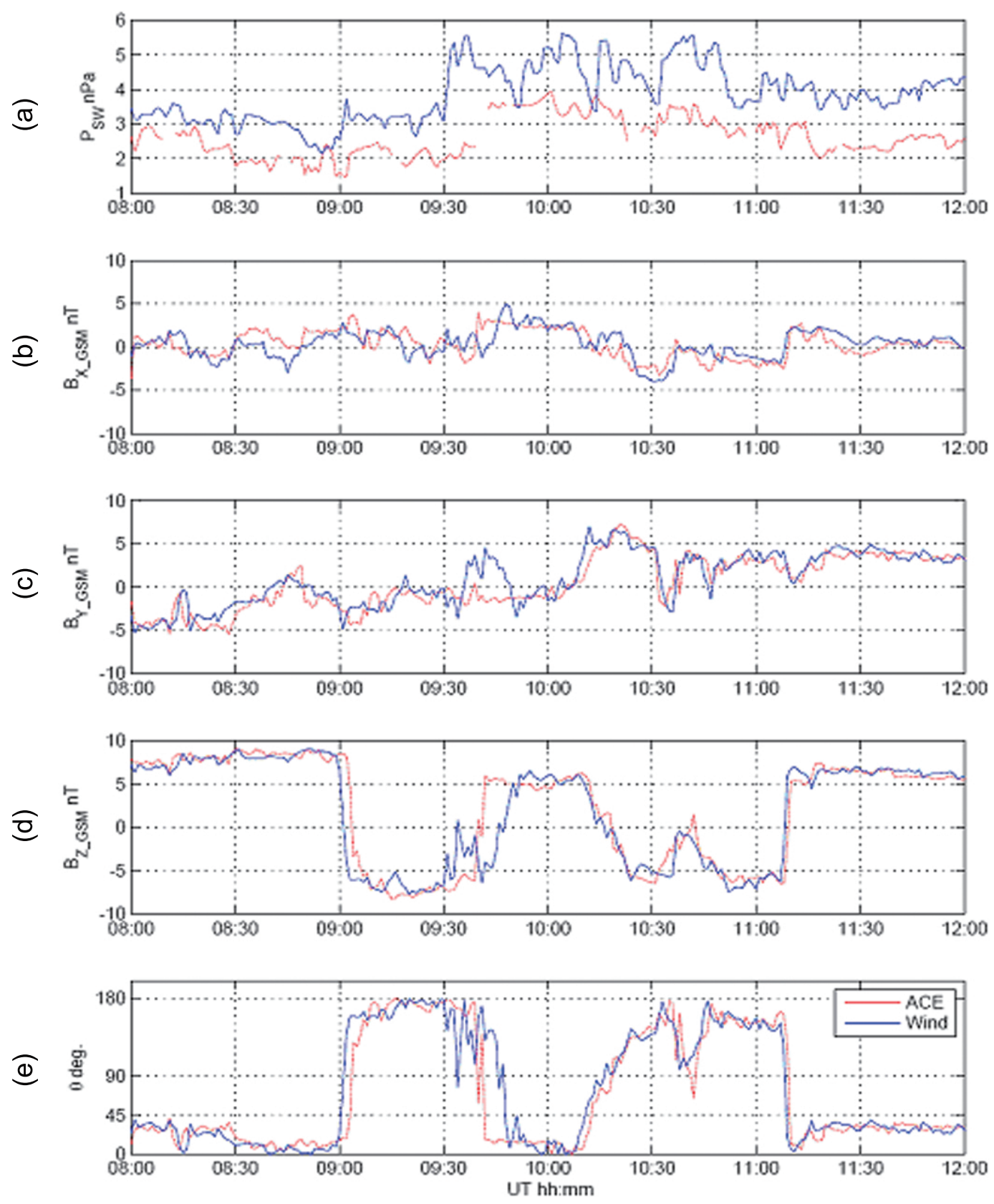

Fig. 3. Lagged solar wind observations at the nose of the bow shock from the OMNIWeb database. ACE data are shown in red, Wind in blue. Solar wind dynamic pressure is displayed in panel (a). The three components of the IMF vector in GSM coordinates are shown in panels (b) to (d). The lower panel (e) presents the IMF clock angle.

During the interval of interest, the IMF $B_{Z}$ component underwent four reversals, as shown in panel (d) of Fig. 3. Initial conditions were characterised by a steady and strongly northward IMF, with $\theta<45^{\circ}$ (panel e). The IMF clock angle then rotated rapidly, exceeding $90^{\circ}$ at 09:01 UT, indicating the first southward turning. About $45 \mathrm{~min}$ later, $B_{Z}$ returned northward, with $\theta \sim 30^{\circ}$. Around the time of this second rotation, which was observed some 10 min later by Wind than by ACE, the solar wind dynamic pressure monitored by both spacecraft increased nearly by a factor of two (panel a). The third IMF $B_{Z}$ turning, back to a southward orientation, occurred at around 10:18 UT, albeit more slowly than the two previous turnings. Subsequently, after having been southward for nearly $50 \mathrm{~min}$, the $B_{Z}$ component turned rapidly northward, for a second time, near 11:08 UT. The IMF $B_{Y}$ component was predominantly negative prior to $10: 15 \mathrm{UT}$ 


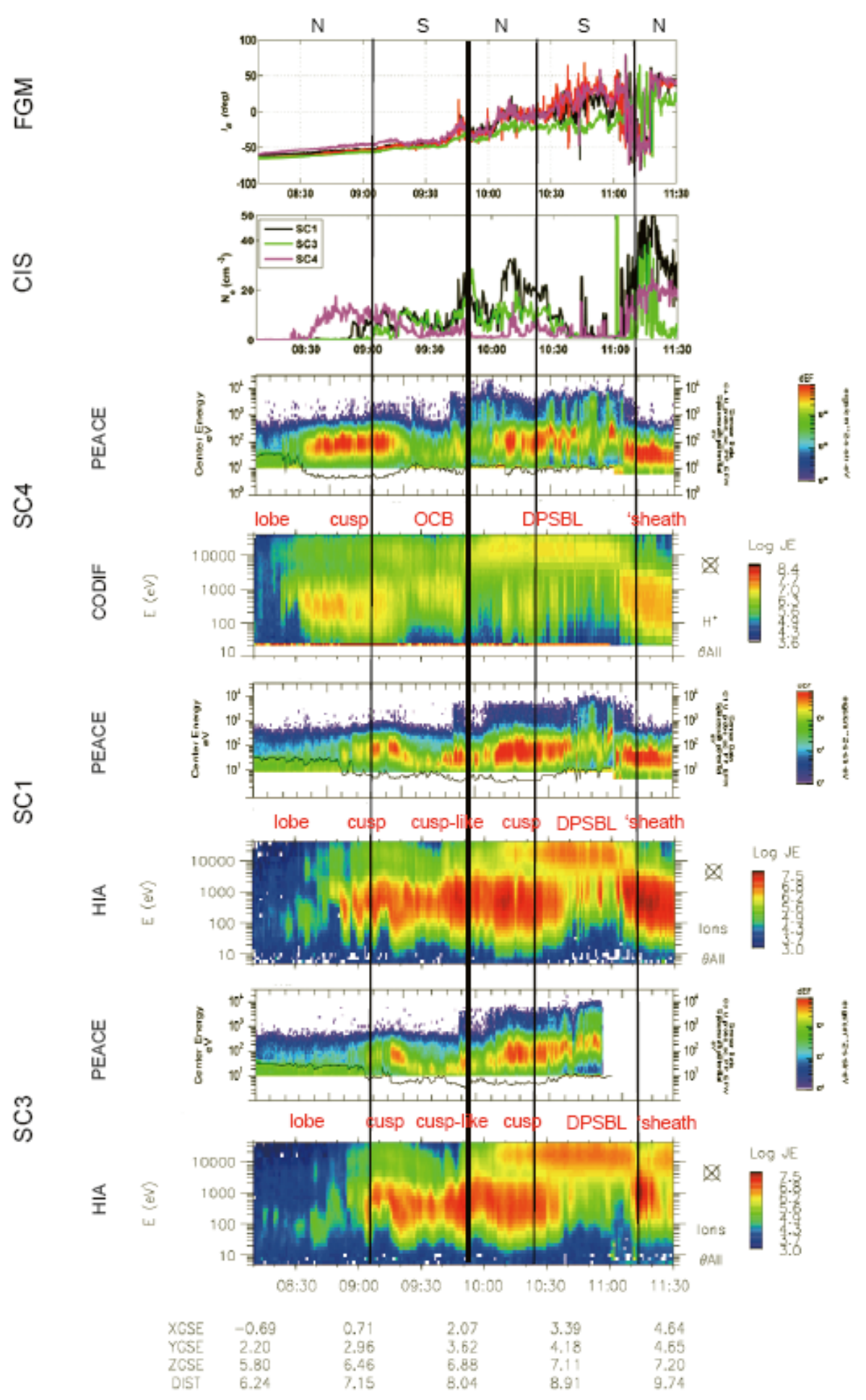

Fig. 4. Cluster FGM, PEACE and CIS data from 08:10 to 11:30 UT on 12 February 2003. The times of IMF polarity reversals, derived from the Wind observations but lagged to the location of Cluster, are marked by vertical black lines. IMF conditions are indicated by "N" (for northward) and "S" (southward) at the top of the figure. Successive regions crossed by each spacecraft are indicated below each panel of PEACE data. See details in the text. 
and positive thereafter. Over the majority of the interval, the IMF was dominated by its $B_{Z}$ component. The $K_{p}$ geomagnetic index was no higher than 3 throughout the interval.

\subsection{Cluster spacecraft}

Cluster data during the interval 08:10 to 11:30 UT are shown in Fig. 4. The top panel of Fig. 4 presents the magnetic field inclination $\left(I_{B}\right)$ from the FGM instrument (Balogh et al., 1997, 2001) on all four Cluster spacecraft (SC1: black; SC2: red; SC3: green and SC4: magenta). The second panel presents the corresponding ion density from CIS (Rème et al., 2001) for SC1, SC3 and SC4 (the CIS instrument is not operational on $\mathrm{SC} 2$ ). The remaining 6 panels illustrate electron spectrograms from PEACE (Johnstone et al., 1997) and ion spectrograms from the CIS instruments on Cluster SC4, $\mathrm{SC} 1$ and SC3, respectively. The PEACE differential electron energy flux shown is that parallel to local magnetic field. The CIS data from $\mathrm{SC} 1$ and $\mathrm{SC} 3$ are from the HIA experiment, whereas those from SC4 are from CODIF, since HIA does not work on that spacecraft. The CODIF instrument provides the mass per charge composition with an angular resolution of $22.5^{\circ}$; HIA does not provide mass resolution but has a better angular resolution (Rème et al., 2001). Note that whereas the CIS-HIA data presented in this paper are from all ions, the CODIF data are from the $\mathrm{H}^{+}$ions (i.e. protons) only. Vertical lines indicate the times at which the IMF $B_{Z}$ reversals are expected to reach Cluster: an additional four minutes is included relative to the transit time to the bow shock included in the OMNIWeb data.

\subsubsection{Cluster spacecraft 4}

Observations from SC4, which led the Cluster formation and cut deeper into the cusp and dayside magnetosphere, are selected to first illustrate the successive regions crossed by Cluster during the interval of interest. Initially, Cluster SC4 was in the northern lobe characterised by a low ion density, $\sim 0.01 \mathrm{~cm}^{-3}$, and low plasma $\beta \sim 10^{-3}$ (not shown). At around 08:32 UT, SC4 entered the high-altitude cusp, evidenced by an increase in plasma density (up to $15 \mathrm{~cm}^{-3}$ ) and the presence of typical magnetosheath-like ion fluxes $(\sim 100 \mathrm{eV}-1 \mathrm{keV})$ in the CIS data. Cusp entry was also fairly clear in the PEACE data, corresponding to an enhancement in the electron fluxes with energies from tens to several hundred eV. Entry into the cusp was less recognisable in the FGM data, as the magnetic field strength was continuously decreasing during this period, although there was a corresponding increase in the level of magnetic field fluctuations. At the poleward edge of the cusp, CIS detected downwardmoving $\mathrm{H}^{+}$ions, with $V_{Z} \sim-150 \mathrm{~km} / \mathrm{s}$ in the GSM coordinate system. Inside the cusp, CIS observed a number of ion injections, displaying a hint of reversed ion dispersion, whereas PEACE observed relatively steady electron fluxes, typical of cusp populations (Lavraud et al., 2004; Bogdanova et al., 2006). Plasma convection remained weakly tailward, with $V_{X} \sim-30 \mathrm{~km} / \mathrm{s}$, throughout the initial period of northward IMF.

The cusp crossing by Cluster SC4 lasted for a period of about $40 \mathrm{~min}$, the spacecraft exiting the cusp at around 09:17 UT after the first IMF southward turning. After this southward turning, the equatorward edge of the cusp might be expected to move to lower latitude; the motion of Cluster SC4 along its track meant, however, that it would inevitably cross into the high-latitude dayside closed field line region (see Fig. 1). The exit of SC4 from the cusp proper was identified by a reduction in the magnetosheath-like particle fluxes which, although clear in the PEACE observations, was somewhat less clear in the CIS data. Between 09:20 and 09:50 UT, after having exited the cusp, SC4 flew through a region characterised by relatively low fluxes of both ions and electrons. This region would appear to represent the development of a boundary layer on the equatorward edge of the cusp, during southward IMF conditions, having lower flux and higher ion temperature and perhaps marking the open-closed field line boundary $(\mathrm{OCB})$.

Subsequently, at 09:50 UT, SC4 encountered a region marked by the clear presence of magnetospheric-like ions. At this time, the ion temperature was greatly enhanced, from about $700 \mathrm{eV}$ to $4 \mathrm{keV}$. Within this region, the electrons, as measured by PEACE, were primarily of magnetosheath-like energies, implying that SC4 was likely to be still in the boundary layer. The second IMF reversal (back to northward) was expected to reach SC4 around 09:51 UT, after the spacecraft had entered into the region of dayside closed field lines. As we have already noted, a strong increase in the solar wind dynamic pressure occurred around the time of this second reversal, back to IMF north.

Many transient events were observed before SC4 finally crossed the magnetopause into the magnetosheath at around 11:02 UT. The majority of these occurred at a time which coincided closely with the second cusp encounter by Cluster $\mathrm{SC} 1$ and 3 (we will discuss this in detail later), after the dynamic pressure increase. They could, therefore, have resulted from a compression of the magnetosphere, which would have had the effect of moving the magnetopause boundary inwards such that SC4 moved nearer to the outer cusp boundary.

It should be noted that the response of the high-latitude and exterior cusp region is likely to be different from the low-altitude cusp and ionospheric response (see Sect. 2.3). Dayside reconnection is expected to widen the cusp throat, while compression may move it to lower latitudes (Pitout et al., 2006). SC4 therefore appeared to sample a predominantly spatial sequence during its traversal, crossing the poleward cusp boundary during stable northward IMF conditions and crossing the equatorward cusp boundary (OCB) during southward IMF conditions. 


\subsubsection{Cluster spacecraft 1 and 3}

Cluster SC1 and SC3 entered the cusp later than SC4 by around 20 and $30 \mathrm{~min}$, respectively. Thus, the first IMF southward turning occurred while SC1 and SC3 were located near the poleward edge of the cusp. When within the cusp, these spacecraft initially observed distinct ion injections clearly exhibiting reversed dispersion, indicating that a site of magnetic reconnection was located poleward of the spacecraft. Unlike that of SC4, the cusp exits of SC1 and SC3 were far from clear in the CIS data, since these spacecraft observed temporal as well as spatial changes. At these times, however, PEACE observed clear reductions in the flux of magnetosheath-like electrons, accompanied by a progressive decrease in the mean electron energy. Both SC1 and SC3 appeared to enter the inner boundary layer at around 10:36 UT, so it is likely that they crossed the equatorward cusp boundary under southward IMF conditions.

Cluster particle observations between 09:40 and 10:30 UT suggest that $\mathrm{SC} 1$ and $\mathrm{SC} 3$ crossed quite different regions from SC4 during this interval. In particular, a different cusp configuration was crossed by $\mathrm{SC} 1$ and $\mathrm{SC} 3$ from 10:05 to 10:30 UT, following the IMF northward rotation near 09:51 UT. We refer to this region as the cusp because typical magnetosheath-like ion and electron fluxes were detected inside, with a high plasma density, up to $30 \mathrm{~cm}^{-3}$. This region was encountered by the spacecraft after the solar wind dynamic pressure had increased by a factor approaching two, as mentioned above; this pressure increase was expected to reach Cluster at around 09:34 UT. We can attribute the cusp entry of SC1 and SC3 to the resultant compression of the magnetosphere, moving the magnetopause inwards so that these spacecraft, like SC4, effectively moved out into the exterior cusp region during the period of northward IMF.

Unlike in the earlier cusp encounter around 09:00 UT, ion dispersion signatures were absent and the particle fluxes remained fairly consistent throughout this region. In addition to a magnetosheath-like population, magnetosphericlike ions were also detected, suggesting that the cusp was likely to be on closed field lines. As noted above, the cusp entry at 10:05 UT was under northward IMF conditions, when the cusp boundary was likely to be moving to higher latitudes. At around 10:27 UT, both SC1 and SC3 exited the cusp into the cusp/dayside plasma sheet boundary layer (DPSBL) during southward IMF, a region characterized by the presence of field-aligned bi-directional streaming electrons of $20-500 \mathrm{eV}$ (not shown). In this region, the ion temperature was relatively low $(<1 \mathrm{keV})$. The inner boundary layer of the dayside plasma sheet was encountered at $\sim 10: 36 \mathrm{UT}$, indicated by a sharp enhancement of ion temperature (up to $5 \mathrm{keV}$ ) and a reduction in the flux of magnetosheath-like ions.

Prior to the second cusp crossing, during the interval extending from 09:40 to 10:05 UT, SC1 and SC3 traversed a region similar to the cusp in character. At about 09:43 UT, magnetospheric-like electrons $(>1 \mathrm{keV})$ were observed by the PEACE instrument. The inclination of the magnetic field reduced at around 09:45 UT in association with a transient decrease in field magnitude. In this region, a high ion density, up to $20 \mathrm{~cm}^{-3}$, was detected, as well as the presence of magnetosheath-like ions with no obvious signatures of dispersion. In contrast to that associated with the two previously mentioned cusp encounters, the ion temperature in this region showed no notable variations, however, the magnetosheath-like electron population was slightly colder, with energies no higher than $100 \mathrm{eV}$.

The Cluster SC1 and SC3 observations before 10:05 UT were indicative of temporal variations occurring on the poleward side of the high-altitude cusp; the spacecraft only encountered the equatorward cusp boundary some time after the second IMF reversal, back to northward IMF. We infer that, due to the different orientations of the polar and equatorward boundaries of the high-altitude cusp region, $\mathrm{SC} 1$ encountered the poleward boundary earlier than $\mathrm{SC} 3$, whereas both spacecraft (SC1 and SC3) crossed the equatorward cusp boundary and entered the dayside plasma sheet boundary layer at almost the same time.

Near 11:18 UT, all Cluster spacecraft crossed the magnetopause, and subsequently sampled a sharp solar wind discontinuity, as indicated by the abrupt rotation in the $B_{X}$ and $B_{Z}$ components sampled by FGM. The normal direction derived using the Minimum Variance Analysis (MVA) technique (Sonnerup et al., 1967) applied to FGM data from SC1 yields $n=(0.690 ; 0.123 ; 0.713)$ in GSM coordinates, which we expect to be close to the magnetopause orientation. The application of the Planar Discontinuity Analysis Method to the magnetic field time series (Dunlop et al., 1997) gives an average normal speed of $\sim 70 \mathrm{~km} / \mathrm{s}$.

\subsection{ESR and EISCAT VHF radars}

Figure 5 illustrates observations from the ESR and EISCAT VHF radars from 08:00 to 12:00 UT. Panel (a) presents electron density measured by the $32 \mathrm{~m}$ dish of the ESR, the beam of which was directed at $30^{\circ}$ elevation towards the magnetic pole. Panels (b) and (c) present electron density and electron temperature measured with the ESR $42 \mathrm{~m}$ antenna, pointing in the field-aligned direction, while panels (d) and (e) show the line-of-sight plasma velocity (positive away) measured using the ESR $32 \mathrm{~m}$ dish and the VHF radar, respectively. Parameters are plotted in a time versus altitude format for the ESR $42 \mathrm{~m}$ data, and as time versus geographic latitude for the ESR $32 \mathrm{~m}$ and VHF radars. A short gap in the ESR data after 08:04 UT represents a brief interruption in radar transmission. The four vertical lines show the lagged times at which the changes in direction of the IMF $B_{Z}$ component are predicted to reach the ionosphere, dividing the plot into five numbered sub-intervals. The appropriate time lag was calculated using the OMNIWeb estimate of the solar wind transit time to the nose of the bow shock (derived from solar wind 


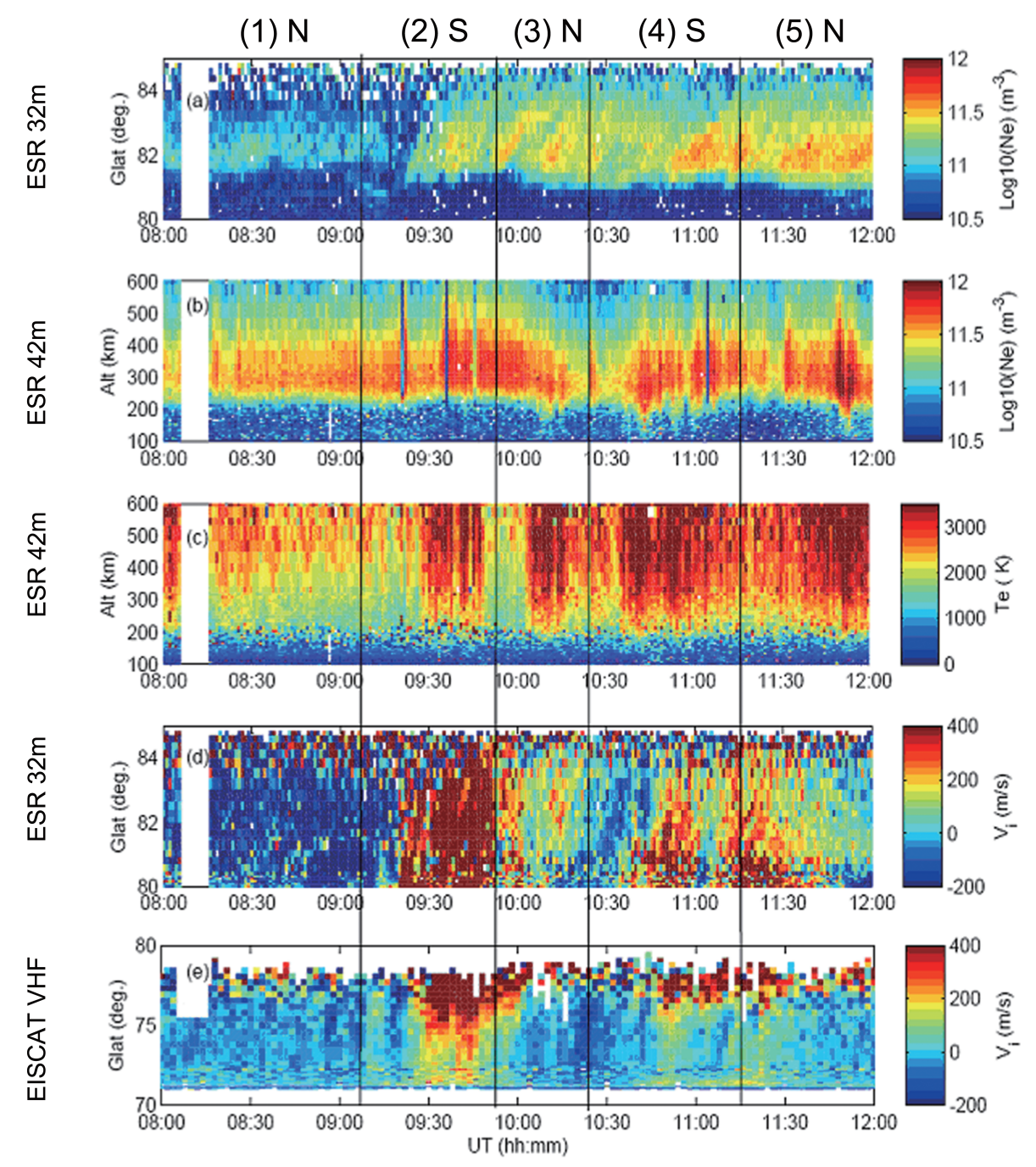

Fig. 5. Ionospheric observations from the ESR and EISCAT VHF radars during the interval 08:00 to 12:00 UT on 12 February 2003. The four vertical lines represent the times at which the IMF polarity changes are expected to be detected in the ionosphere. At the top of the figure, each of the 5 sub-intervals is numbered, and its IMF orientation noted (N: north, S: south). Panels (a) to (d) present observations from the ESR radars and (e) shows data from the EISCAT VHF radar.

velocity data) with a further six minutes added to allow for propagation of solar wind effects across the magnetosheath and down to the ground.

During interval (1), characterised by northward IMF, the ESR $32 \mathrm{~m}$ dish observed a low-density F-region with little obvious structure, while the $42 \mathrm{~m}$ dish measured typical Fregion densities of around $3 \times 10^{11} \mathrm{~m}^{-3}$ and electron temperatures around $2500 \mathrm{~K}$. The velocity measurements made by the ESR $32 \mathrm{~m}$ and EISCAT VHF radars suggest that convection was primarily sunward. At this time, the Cluster observations confirmed that the cusp was located poleward and geographically eastward of Svalbard, and was not intersected by any of the EISCAT beams. Thus, EISCAT observed sunward convection equatorward of the cusp, on closed field lines.
During interval (2), following the southward turning in $B_{Z}$, the electron density observed by both ESR antennas increased significantly, and a series of poleward-moving density structures was detected by the $32 \mathrm{~m}$ dish, consistent with the idea that field lines, reconnected at low latitudes under $B_{Z}$ southward conditions, were being convected antisunward through the polar cap. A marked increase in electron temperature was measured by the ESR $42 \mathrm{~m}$ dish near 09:30 UT, which we suggest to be the signature of the OpenClosed field line Boundary (OCB) as it expanded over the radar (Lockwood et al., 2005). This inference is supported by an intensification in the anti-sunward convection observed by the ESR $32 \mathrm{~m}$ radar (panel d) and the presence of an expanding region of anti-sunward flow detected by the Troms $\varnothing$ VHF radar (panel e). Around 09:46UT, a second sharp electron 
temperature boundary (this time a reduction) was observed by the ESR $42 \mathrm{~m}$ radar, suggesting that the cusp precipitation had either ceased or had moved to a location equatorward of the radar; the IMF $B_{Z}$ continued to be strongly southward.

The convection measured by the Troms $\varnothing$ VHF radar (panel e) responded quickly to the northward turning in the IMF at the start of interval (3), although poleward-moving density structures continued to be seen in the ESR $32 \mathrm{~m}$ data as fossil remnants of earlier (southward IMF) reconnection events (panel a). A second distinct electron temperature increase was observed by the ESR $42 \mathrm{~m}$ radar (panel c) at 10:06 UT, which can be interpreted in terms of the region of cusp precipitation crossing back over Svalbard in response to the northward turning in IMF $B_{Z}$. By the end of interval (3) poleward-moving density structures were no longer observed by the ESR $32 \mathrm{~m}$ radar (panel a), cusp-type density enhancements were no longer detected by the ESR $42 \mathrm{~m}$ dish (panel b), and the convection measured by the ESR $32 \mathrm{~m}$ (panel d) and Troms $\varnothing$ VHF radars (panel e) had become dominated by sunward flow, all as expected for $B_{Z}$ north conditions.

Interval (4), following the second southward turning in $B_{Z}$, was comparable with interval (2) in that polewardmoving density structures reappeared in the polar cap, as observed by the ESR $32 \mathrm{~m}$ dish (panel a), cusp-like density and temperature signatures once again became evident in the ESR $42 \mathrm{~m}$ data (panels $\mathrm{b}$ and c), and anti-sunward flow reappeared in the ESR $32 \mathrm{~m}$ data (panel d) and in the northernmost ranges of the mainland VHF data (panel e). It is interesting to note that there is a short time period around 10:40 UT during which both anti-sunward and sunward flows were observed along the line of sight of the $32 \mathrm{~m}$ dish. Such a feature of plasma convection has previously been interpreted as either the signature of reconnection taking place simultaneously poleward and equatorward of the cusp (Pitout et al., 2002), or just as a transition phase after an IMF rotation (Pitout et al., 2006).

Around 11:15 UT, the IMF $B_{Z}$ component turned northward once again. The initial period of interval (5) can be compared to the beginning of interval (3) with the apparent persistence of poleward-moving density signatures in panel (a). However the progressively later magnetic local times of these intervals make us wary of interpreting the ESR data in terms of the cusp response to changing IMF conditions, despite the fact that the prevailing positive values of IMF $B_{Y}$ would favour a cusp displaced toward the postnoon sector (Cowley et al., 1992). We note that the closest predicted magnetic conjugacy between Cluster and the ESR occurred shortly after 11:00 UT ( 14:00 MLT), around the time that the CIS data showed that all of the Cluster spacecraft were passing out into the dayside magnetosheath.

In summary, the observations from the EISCAT VHF radar, and from both dishes of the ESR, showed clear responses to the changes in IMF $B_{Z}$ direction. Some of these responses were delayed, such as the poleward-moving den-

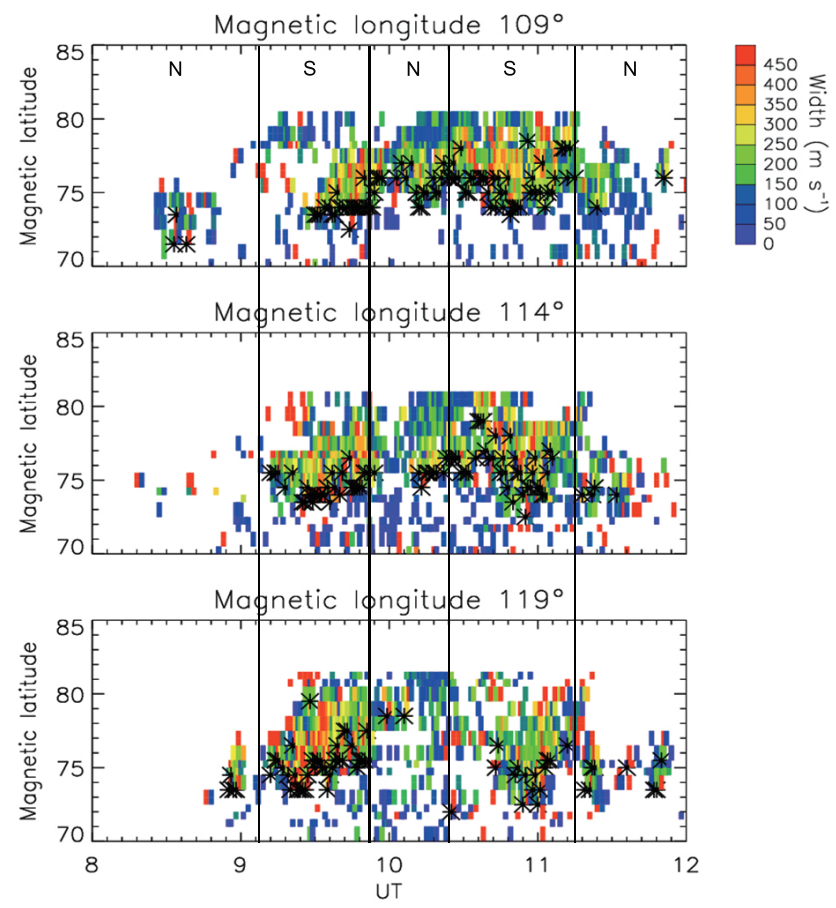

Fig. 6. SuperDARN Pykkvibaer HF radar spectral width as a function of UT and magnetic latitude along a magnetic meridian westward of $\left(109^{\circ}\right)$, over $\left(114^{\circ}\right)$ and eastward $\left(119^{\circ}\right)$ of Svalbard, respectively. The four vertical lines, as well as symbols in the top panel of the figure, are the same as those in Fig. 5. Dark asterisks in the figure mark the equatorward boundary of the cusp scatter, deduced from the HF radar echoes.

sity structures seen by the ESR $32 \mathrm{~m}$ dish, whose motion took more than $10 \mathrm{~min}$ to become established for $B_{Z}$ south conditions, and equally took a similar time to decay following a northward turning. Some of the responses were complex, for instance the modulation of electron density and temperature in the ESR $42 \mathrm{~m}$ data as features expanded and contracted over the radar site.

\subsection{SuperDARN}

The SuperDARN CUTLASS radars at Hankasalmi (Finland) and Pykkvibaer (Iceland East) provide an extremely useful continuous monitor of HF coherent backscatter location, convection velocity and spectral width over the European sector of the polar ionosphere (Greenwald et al., 1995). The spectral width parameter, in particular, has been identified as an important indicator of the cusp location in a number of previous studies, with high spectral width indicating cusp scatter (e.g. Davies et al., 2002; Woodfield et al., 2002a, b, c). In addition, the observations contributed by the other radars of the worldwide SuperDARN network help to constrain the high-latitude convection pattern, whose shape and extent also provide further powerful clues to the location of the cusp. 
(a) DMSP F14

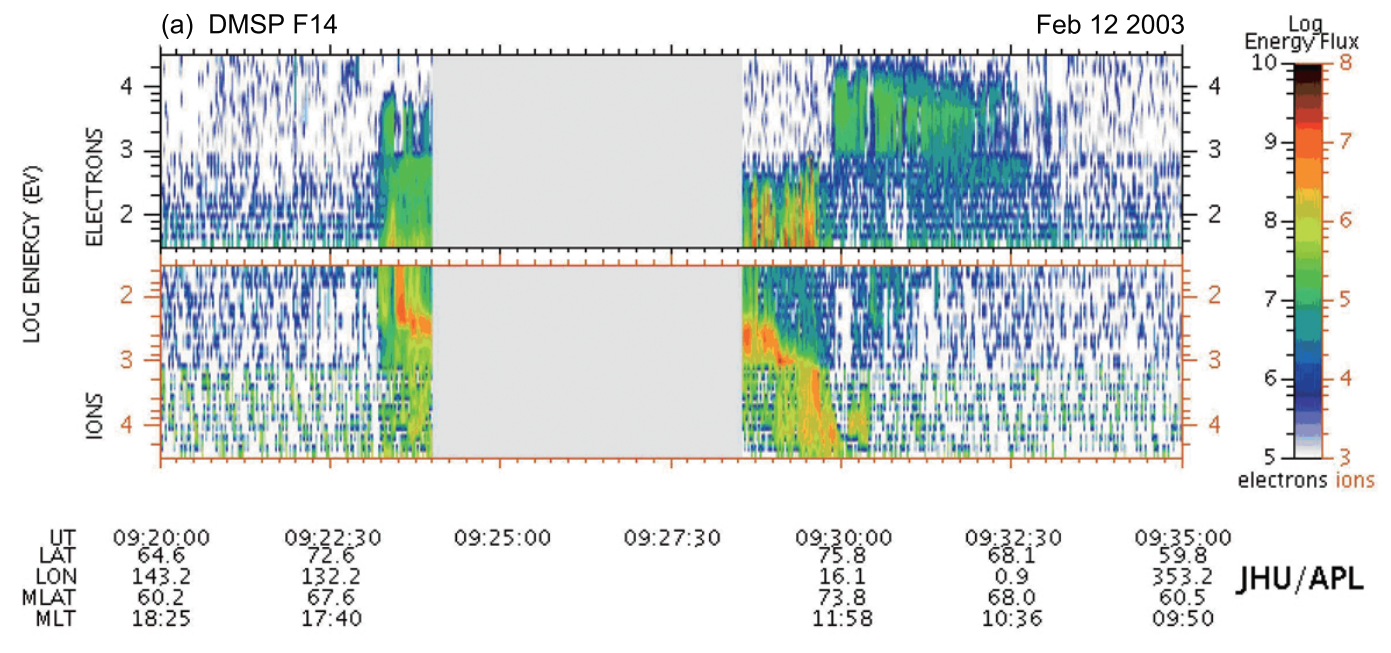

(b) DMSP F13

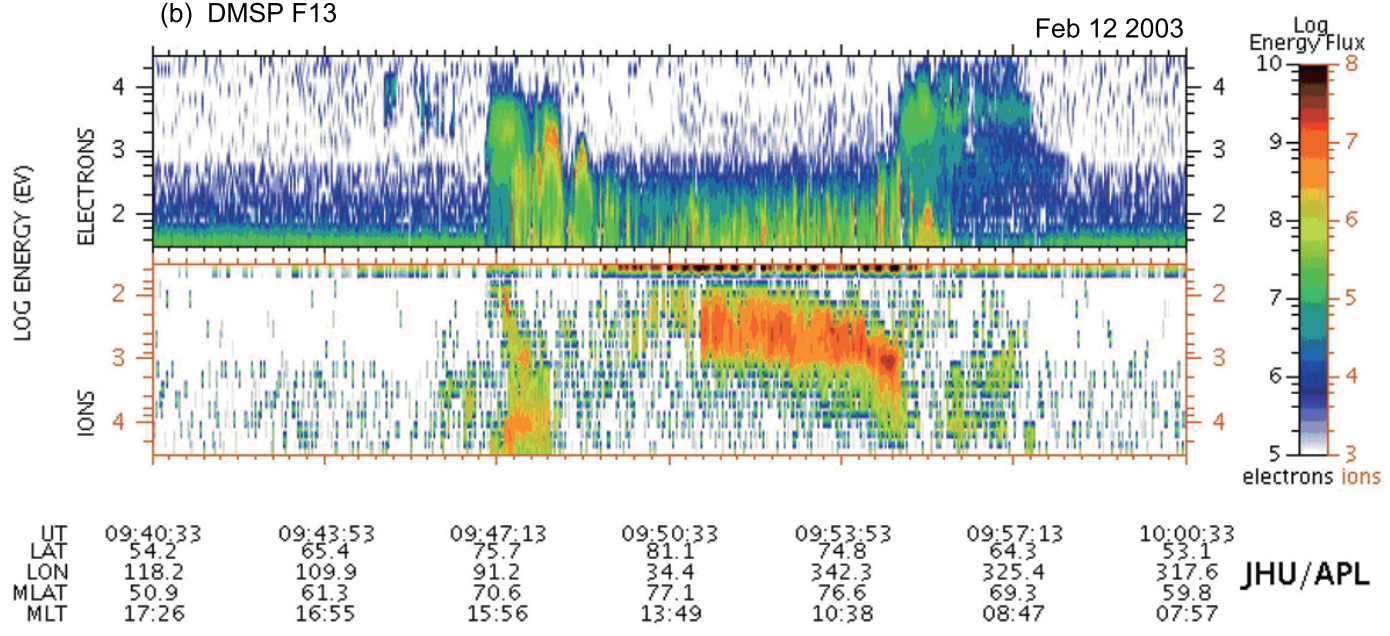

Fig. 7. Ion and electron spectrograms from DMSP F14 between 09:20 and 09:35 UT (upper panel) and from DMSP F13 between 09:40 and 10:00 UT (lower panel).

Although very little ionospheric HF scatter was observed by the Hankasalmi radar, the Pykkvibaer (Iceland East) data revealed the cusp location during the period under study. Figure 6 shows the coherent scatter spectral width as a function of magnetic latitude at three fixed magnetic longitudes during the interval of interest, as measured by the Pykkvibaer radar. The values of the three fixed magnetic longitudes are selected to illustrate HF scatter along a magnetic meridian westward of $\left(109^{\circ}\right)$, over $\left(114^{\circ}\right)$ and eastward of $\left(119^{\circ}\right)$ Svalbard. The equatorward boundary of the cusp, indicated by the southern edge of the region of high spectral width (e.g. Yeoman et al., 2002), is also indicated by dark asterisks in the figure. The latitude of the equatorward cusp boundary is determined along each magnetic meridian by requiring that three adjacent "pixels" in latitude have a spectral width greater than $150 \mathrm{~m} / \mathrm{s}$. This avoids the false identification associated with noise. The four vertical lines in Fig. 6 are the same as those in Fig. 5. The time resolution of the HF radar observations is $1 \mathrm{~min}$.
During interval 1, before 09:00 UT, when $B_{Z}$ was northward, the CUTLASS Pykkvibaer radar detected very little ionospheric backscatter of any kind over Svalbard. In interval 2, after the IMF southward turning, ionospheric scatter with high spectral width became increasingly evident around $75^{\circ}$ magnetic latitude, appearing first at more eastward longitudes. It is likely that this region of high spectral width backscatter corresponded to the cusp. Subsequently during interval 3, from around 09:52 UT when the IMF returned northward, the equatorward boundary of this region of backscatter appeared to retreat poleward. During the following $30 \mathrm{~min}$ interval, a smaller region of cusp scatter appeared to be primarily situated at longitudes west of Svalbard, although there is a suggestion that Svalbard remained close to its eastern boundary.

After around 10:24 UT (interval 4) when the IMF had again turned southward, a longitudinally extended region of high spectral width ionospheric backscatter, again indicative of the cusp, was detected by the CUTLASS Pykkvibaer 
radar, expanding down to $\sim 73^{\circ}$ magnetic latitude. As in the interval prior to 09:00 UT, when $B_{Z}$ was also northward, the final interval of $B_{Z}$ northward (interval 5) was characterised by a lack of ionospheric scatter.

It is clear from Fig. 6 that the equatorward boundary of the HF radar cusp moved back and forth in latitude in response to the IMF polarity changes. There were minor differences in the form of this variation between the three selected magnetic meridians, likely to be caused by longitudinal displacement of the cusp due to the IMF $B_{Y}$ component.

\subsection{DMSP}

Figure 7 shows observations from two Northern Hemisphere passes of the DMSP spacecraft. The upper panel presents electron and ion energy spectrograms from DMSP F14 during the interval extending from 09:20 to 09:35 UT. Although there is, unfortunately, a data gap from 09:24 to 09:27 UT, the most relevant interval here is that between 09:28 and 09:30 UT when the footprint of the spacecraft was slightly equatorward of the ESR (see Fig. 2) under $B_{Z}$ south conditions. The spacecraft encountered the OCB at 11:58 MLT, at $\sim 73.8^{\circ}$ magnetic latitude, indicated by the appearance of magnetospheric $(>1 \mathrm{keV})$ electrons and the disappearance of magnetosheath-like $(<1 \mathrm{keV})$ electrons (Newell et al., 1988). A Low-Latitude Boundary Layer-like region was observed poleward of the OCB, inside which both magnetosheath-like and magnetosphere-like ion populations were detected. Notably, magnetosphere-like ions were observed directly poleward of the boundary, suggesting that magnetic reconnection was likely to be ongoing at the section of the OCB intersected by the spacecraft (Lockwood et al., 1995).

DMSP F13 observations of the northern polar regions between 09:40 and 10:00 UT are displayed in the lower panel of Fig. 7 (note the track shown in Fig. 2). During this pass, the satellite skimmed the dayside ionosphere close to the magnetic noon meridian, reaching a maximum magnetic latitude of approximately $77.1^{\circ}$. During the interval from 09:51 to 09:54 UT, F13 crossed a region, poleward of $76^{\circ} \mathrm{mag}$ netic latitude, inside which relatively cold $(\sim 100 \mathrm{eV})$ electron precipitation was observed. We identify this region as the cusp, since it was characterised by a significant flux of $100 \mathrm{eV}$ to $10 \mathrm{keV}$ ions. These ions exhibited typical dispersion, in that the ion average energy increased as latitude decreased. The DMSP F13 spacecraft intersected the ESR $32 \mathrm{~m}$ radar beam around 09:52 UT, close to $76.3^{\circ}$ magnetic latitude, around which time the radar was observing polewardmoving plasma structures in the polar cap, which likely originated in the cusp/cleft region due to pulsed magnetic reconnection (Lockwood et al., 1998; Davis et al., 1996).

\section{Discussion}

\subsection{The northward IMF cusp}

As shown in Sect. 2.2, Cluster SC1 and SC3 crossed the high-altitude cusp twice before finally exiting into the magnetosheath, both crossings being under northward IMF conditions. Although the following paragraphs refer only to Cluster SC1, the same regions were crossed by Cluster SC3, and the observations from that spacecraft can be interpreted similarly.

During both encounters, the poleward edge of the cusp appeared to be quite sharp, as indicated by the rapid enhancement in plasma density (Fig. 4). It is interesting to note that the first high-latitude cusp crossing was made by all Cluster spacecraft, whereas the second crossing was missed by SC4. During the first cusp crossing, the ions exhibited behaviour typical of positive IMF $B_{Z}$, in agreement with the statistical study of Lavraud et al. (2005). The second cusp crossing, however, appeared to be quite different from the previous one, with rather steady ion fluxes and no evident ion dispersion. Note that the IMF histories leading up to the two cusp crossings were very different: strongly northward IMF persisted for about an hour before SC1 first encountered the cusp, whilst Wind detected around 40 min of steadily southward $B_{Z}$ before a reversal back to IMF north associated with the second cusp crossing. In this section, we will focus on the second cusp crossing and the possible formation mechanism of the cusp at that time.

Prior to the second cusp encounter, between 09:40 and 10:05 UT, Cluster SC1 crossed a region similar in character to the cusp. In this region, a high ion density, exceeding $20 \mathrm{~cm}^{-3}$, was detected, as well as significant magnetosheathlike ion fluxes with no obvious dispersion. The ion temperature showed no notable variations, however, and the magnetosheath-like electron population was much colder than that observed during the previous cusp encounter, with energies no higher than $100 \mathrm{eV}$. One has to keep in mind that, at the start of this interval, the IMF was steadily southward before its northward turning at about 09:52 UT.

From 09:50 to 09:54 UT, a typical southward-IMF cusp was observed by DMSP F13 (Fig. 7b). F13 was located directly equatorward of the magnetic footprint of SC1 at 10:00 UT (Fig. 2). In other words, the cusp-like region crossed by SC1 during the interval 09:40 to 10:05 UT was adjacent to, and slightly poleward of, the southward-IMF cusp. The CIS ion observations do not exclude the possibility that the region in which $\mathrm{SC} 1$ was located could have been a part of the cusp. However, most of the cusp electrons detected by DMSP F13, had mean energies higher than $100 \mathrm{eV}$ (Fig. 7b), whereas the PEACE instrument on Cluster $\mathrm{SC} 1$ detected fluxes of rather colder electrons, with energies generally no higher than $100 \mathrm{eV}$. Therefore, we identify the region traversed by Cluster SC1 between 09:40 and 10:05 UT as being the poleward boundary layer. 

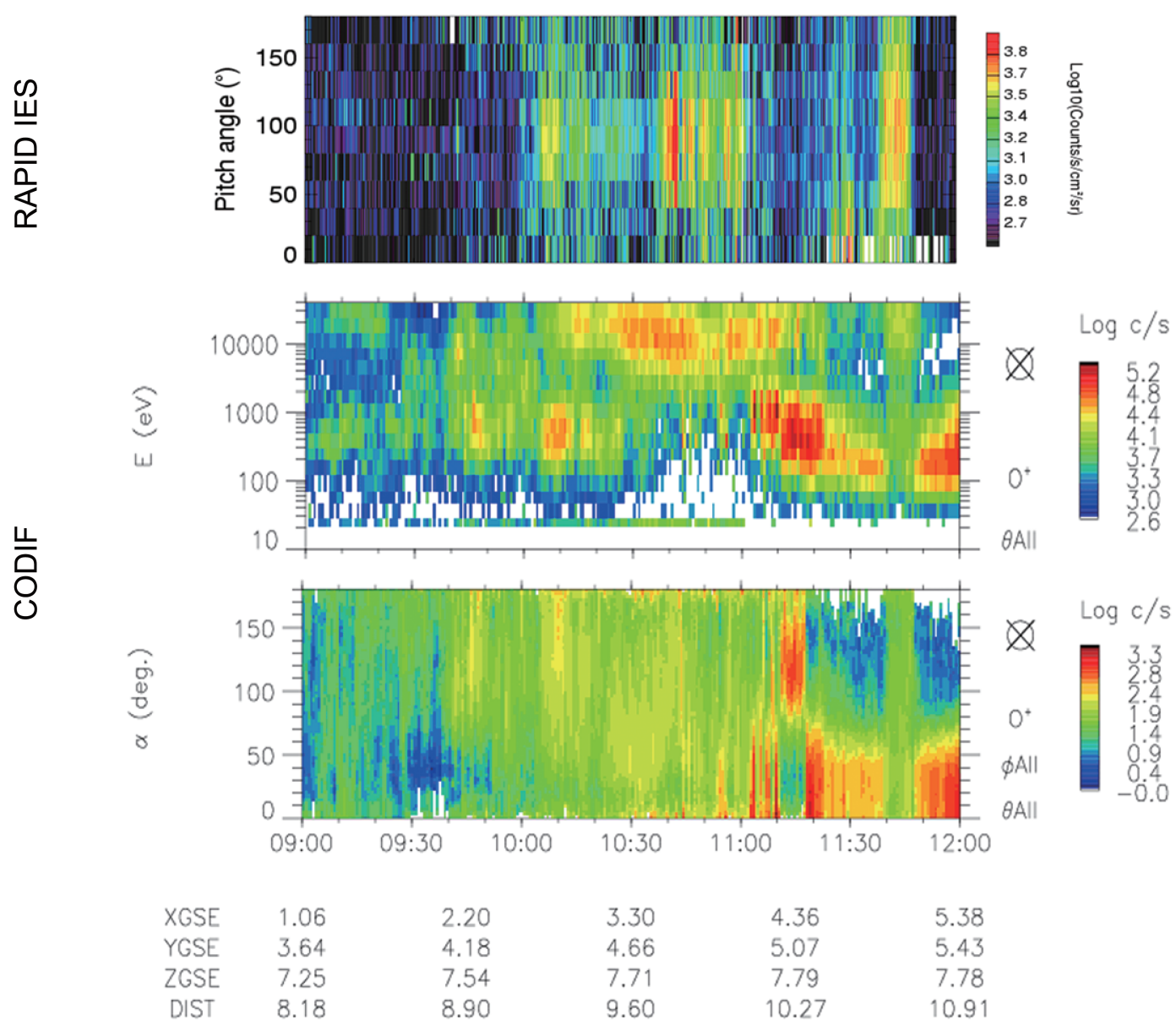

Fig. 8. RAPID IES and CODIF observations from SC1. The top panel presents the suprathermal electron flux as a function of UT and pitch angle from RAPID-IES. Subsequent panels present the $\mathrm{O}^{+}$flux from CODIF, the energy (middle panel) and pitch angle (bottom panel) as a function of UT. See text for details.

Cluster SC1 encountered the northward-IMF cusp for a second time at around 10:05 UT, at a location some $2 R_{E}$ sunward, along the spacecraft trajectory, of the previous cusp crossing near 09:00 UT. This second encounter with the northward-IMF cusp, unlike the previous one, was characterised by rather steady ion fluxes, with no obvious dispersion. The ion pitch angle distribution revealed no dramatic variations, except for a brief excursion into the magnetosphere around 10:14 UT. The IMF clock angle was small $\left(\theta<10^{\circ}\right)$ as the spacecraft entered the cusp, and increased gradually to almost $90^{\circ}$ before its cusp exit.

The top panel of Fig. 8 displays the pitch angle distribution of suprathermal electrons, as a function of time, observed by the RAPID IES instrument on Cluster SC1. Subsequent panels present the energy spectrogram and pitch angle distribution of $\mathrm{O}^{+}$from CODIF on the same spacecraft. One has to bear in mind that the presence of strong fluxes of oxygen ions at the inner boundary of the dayside plasma sheet and the magnetosheath should be treated with some suspicion, as they may be due to "spillover" effects in the ion measurement. Nevertheless, Fig. 8 appears to show bursts of upward-flowing $\mathrm{O}^{+}$ions with energies of several hundred $\mathrm{eV}$ during the interval from 09:40 to 10:30 UT. This is the period during which SC1 traversed the poleward boundary layer of the southward-IMF cusp (09:40-10:05 UT) and then made its second encounter with the northward-IMF cusp (10:0510:30 UT). It is worth reminding the reader that the orientation of the IMF $B_{Z}$ reversed at 09:52 UT, from southward to northward. We interpret these observations as indicating that, throughout the interval from 09:40 to 10:30 UT, SC1 was likely to have been located on field lines opened at a low latitude reconnection site. Before 10:05 UT, these field lines remained open, but after the northward turning, the observations suggest that they were being re-closed by high-latitude reconnection.

During the interval from 09:40 to 10:05 UT, when the IMF $B_{Z}$ was predominantly southward, the field lines sampled by Cluster SC1 did not appear to be closed, since neither magnetospheric ions, or fluxes of high-energy electrons were observed. The ion spectra measured by DMSP F14 from 09:28 
to $09: 30 \mathrm{UT}$ (Fig. 7a) confirmed that magnetic reconnection was ongoing at low latitude; F13 observations from 09:50 to 09:54 UT (Fig. 7b) suggested that the southward-IMF cusp was located equatorward of the magnetic footprint of Cluster SC1. Highly efficient low latitude reconnection was implied by the strongly anti-sunward ionospheric plasma convection observed by the ESR (Fig. 5d and e); the observed ion velocities being up to $1000 \mathrm{~m} / \mathrm{s}$. The ESR $32 \mathrm{~m}$ radar observed clear poleward-moving plasma structures in the polar cap (Fig. 5a), consistent with the strongly anti-sunward ionospheric convection. The newly-opened field lines were thus being swept tailward, across the cusp, due to a combination of solar wind and magnetic tension force. This implies that the oxygen ions detected by SC1 were streaming outward from the polar ionosphere, along open field lines.

During the second northward-IMF cusp crossing (10:0510:30 UT) by SC1 and SC3, poleward-moving structures continued to be observed by the ESR $32 \mathrm{~m}$ dish (Fig. 5a), these being fossil remnants of earlier reconnection events. These "old opened field lines" produced by earlier reconnection events (during the previous interval of southward $B_{Z}$ ), continued to be swept tailward and were then re-closed poleward of the cusp by the lobe reconnection now taking place during the steadily northward IMF. This inference is supported by the presence of trapped $\left(90^{\circ}\right)$ high-energy electrons observed by RAPID (Fig. 8), indicative of a region of closed field lines (Wilken et al., 2001). Note that fairly large pitch angle bins were required to produce the suprathermal electron pitch angle distribution due to the low fluxes involved, which may have broadened the peak around $90^{\circ}$. Nonetheless, we can conclude that the $\mathrm{O}^{+}$ions observed during the second high-latitude cusp crossing (under northward $B_{Z}$ conditions) were likely to be out-flowing from the polar ionosphere along a closed field structure (e.g. Fuselier et al., 2001). It is also interesting to note that these up-flowing $\mathrm{O}^{+}$ fluxes, detected on closed field lines, were much more intense than those observed on open field lines at earlier times.

\subsection{Latitudinal variations of the cusp}

The occurrence of a double cusp during strongly duskward/dawnward and weakly southward IMF conditions was predicted by Wing et al. (2001) and, in the same study, their model prediction was confirmed by DMSP observations. Recently, Cluster observations of multiple cusp crossings have been reported, which were interpreted in terms of temporal rather than spatial effects (Zong et al., 2004, 2008). In the present interval, Cluster crossed the high-altitude cusp twice, both times during steadily northward IMF, before exiting into the magnetosheath, while the IMF $B_{Z}$ component reversed in polarity four times during the period of interest. The location of the cusp is strongly influenced by the IMF $B_{Z}$ component, whilst it is also affected by the solar wind dynamic pressure and the IMF $B_{Y}$ component (Newell et al., 1989; Pitout et al., 2006).

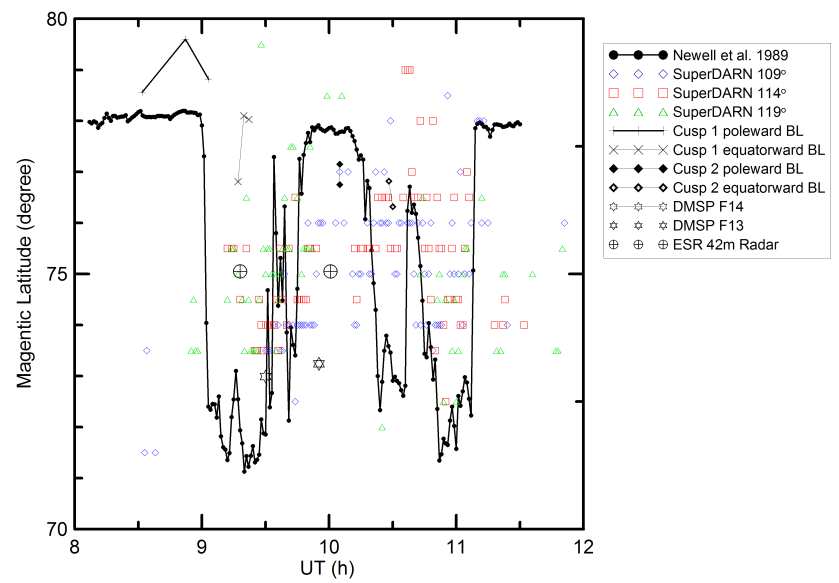

Fig. 9. Cusp boundaries derived from observations by Cluster, DMSP, ESR and the CUTLASS Pykkvibaer radar. The variation of the expected latitudinal location of the cusp is also superposed, based on the work of Newell et al. (1989) with lagged $B_{Z}$ component shown in Fig. 3.

The latitudinal motion of the ionospheric footprint of the high-altitude cusp is apparent in observations from groundbased radars, particularly the SuperDARN Pykkvibaer radar (see Fig. 6). Based on the combined observations from space-borne and ground-based instruments, we infer that the second cusp crossing of Cluster $\mathrm{SC} 1$ and $\mathrm{SC} 3$ was primarily due to the latitudinal migration of the cusp governed by the IMF polarity.

The high-altitude poleward and equatorward cusp boundaries crossed by the Cluster spacecraft during this interval are displayed as a function of magnetic latitude and UT in Fig. 9. The first cusp crossing by Cluster is referred to as "cusp 1" and the second as "cusp 2". The ionospheric footpoints of the high-altitude cusp boundaries were obtained by mapping down along the magnetic field lines of the T96 model. The equatorward boundaries of the cusp, inferred from measurements from DMSP, the $42 \mathrm{~m}$ ESR radar and the CUTLASS Pykkvibaer radar, are also presented in the figure. For comparison, the expected latitudinal position of the cusp equatorward boundary from Newell et al. (1989) is superposed in Fig. 9, based on the lagged $B_{Z}$ component shown in Fig. 3.

Statistical results (e.g. Newell, 1989; Pitout, 2006) suggest that the cusp location is expected to show equatorward (poleward) displacement during southward (northward) IMF, with an average latitudinal position around $75^{\circ}$ magnetic latitude. The latitudinal variation of the equatorward boundary of the cusp, indicated by the southern edge of the high spectral width region observed by the CUTLASS Pykkvibaer radar, is basically in accordance with that predicted by Newell et al. (1989). This implies that the cusp is moving equatorward/poleward in response to the IMF polarity changes. The OCB passed over Svalbard twice during this interval - this was well recorded in observations from the ESR $42 \mathrm{~m}$ dish: 
the first OCB crossing ( 09:30 UT) was due to its equatorward motion under IMF south conditions and the second $(\sim 10: 06 \mathrm{UT})$ was due to its poleward retreat after the IMF had reversed northward. The location of the OCBs deduced from the DMSP F13 and F14 observations agrees well with the latitudinal variation of the cusp discussed above. We therefore interpret the two cusp crossings of Cluster in terms of the latitudinal migration of a single cusp region, rather than as evidence for a double cusp.

Figure 9 shows that Cluster SC4 crossed the poleward boundary of the first high-altitude cusp at $78.6^{\circ}$ magnetic latitude and exited through its equatorward boundary at around $76.8^{\circ}$ magnetic latitude. Boundary crossings by $\mathrm{SC} 1$ and 3 were at higher latitude than those of SC4. Thus, during the first cusp crossing, the ionospheric footprint of the highaltitude cusp is suggested to be located near $78^{\circ}$ magnetic latitude. During the second cusp crossing, Cluster SC 1 crossed the poleward boundary of the cusp at $77.2^{\circ}$ magnetic latitude, whilst SC3 exited the cusp, through its equatorward boundary, at $76.3^{\circ}$ magnetic latitude. At this time, Cluster SC4 mapped to a more southerly magnetic location, at $\sim 74.7^{\circ}$ magnetic latitude. Thus we suggest that, at the time of the second cusp encounter, the cusp region was sufficiently poleward to be crossed by SC1 and 3, but not by SC4. However, we would like to warn that the mapping with Tsyganenko model may not be fully correct, especially in the cusp.

\section{Summary}

This paper has presented the results of a comparative study of the variations in cusp location, during an interval characterised by multiple rapid rotations in IMF $\mathrm{Bz}$, based on observations from the EISCAT VHF and ESR radar, the SuperDARN Pykkvibaer radar, Cluster and DMSP. A series of polarity changes of the $B_{Z}$-dominated IMF provided an excellent opportunity to investigate the response of the magnetosphere-ionosphere system to such conditions, as well as the dynamics in the cusp.

As the IMF $B_{Z}$ component rotated, the cusp was inferred to move back and forth in latitude, in agreement with the predictions of Newell et al. (1989) and Pitout et al. (2006). Consequently, Cluster SC1 and SC 3 crossed the high-altitude cusp twice, both times under strongly northward IMF conditions. The ionospheric response to the series of IMF polarity reversals was well diagnosed by the radars of the EISCAT facility, and the SuperDARN Pykkvibaer HF radar. We conclude that the second Cluster cusp crossing in this case was primarily a result of the latitudinal migration of the cusp in response to prevailing IMF conditions. At this time, the cusp was sufficiently poleward to be crossed by Cluster $\mathrm{SC} 1$ and SC3 but not by SC4.

Although both high-altitude cusp crossing occurred during periods of strongly northward IMF, the cusp ion fluxes exhibited quite different features. The first cusp encounter showed reversed ion dispersion, a typical feature of lobe reconnection. The second cusp crossing, however, was characterised by steady ion fluxes with no obvious dispersion. We suggest that, during the second cusp encounter, Cluster SC1 and SC3 were likely to have been located on newly closed field lines, which were first reconnected (opened) at low latitudes and later reconnected again (closed) poleward of the northern cusp.

Acknowledgements. The authors thank PIs of the CIS (H. Rème), PEACE (A. Fazakerley) and RAPID (P. Daly) instruments onboard Cluster. We are also grateful to the director and staff of the EISCAT Scientific Association for providing the radar facilities and assistance with making the observations. EISCAT is an international scientific association funded by the research councils of China, Finland, Germany, Japan, Norway, Sweden and the UK. ACE and Wind data were obtained from the NASA OMNIWeb. The DMSP particle data were provided by JHU/APL. Hongtao Cai's visit to the Rutherford Appleton Laboratory was supported by the Chinese Scholarship Council.

Topical Editor I. A. Daglis thanks J. Wild and C. P. Escoubet for their help in evaluating this paper.

\section{References}

Balogh, A., Carr, C. M., Acuña, M. H., Dunlop, M. W., Beek, T. J., Brown, P., Fornacon, K.-H., Georgescu, E., Glassmeier, K.H., Harris, J., Musmann, G., Oddy, T., and Schwingenschuh, K.: The Cluster Magnetic Field Investigation: overview of in-flight performance and initial results, Ann. Geophys., 19, 1207-1217, 2001, http://www.ann-geophys.net/19/1207/2001/.

Balogh, A., Dunlop, M. W., Cowley, S. W. H., Southwood, D. J., Thomlinson, J. G., Glassmeier, K.-H., Musmann, G., Luhr, H., Buchert, S., Acuna, M., Fairfield, D. H., Slavin, J. A., Riedler, W., Schwingenschuh, K., and Kivelson, M. G.: The Cluster magnetic field investigation, Space Sci. Rev., 79, 65-91, 1997.

Bogdanova, Y. V., Marchaudon, A., Owen, C. J., Dunlop, M. W., Frey, H. U., Wild, J. A., Fazakerley, A. N., Klecker, B., Davies, J. A., and Milan, S. E.: On the formation of the high-altitude stagnant cusp: Cluster observations, Geophys. Res. Lett., 32, L12101, doi:10.1029/2005GL022813, 2005.

Bogdanova, Y. V., Owen, C. J., Fazakerley, A. N., Klecker, B., and Rème, H.: Statistical study of the location and size of the electron edge of the Low-Latitude Boundary Layer as observed by Cluster at mid-altitudes, Ann. Geophys., 24, 2645-2665, 2006, http://www.ann-geophys.net/24/2645/2006/.

Bogdanova, Y. V., Owen, C. J., Siscoe, G., Fazakerley, A. N., Dandouras, I., Marghitu, O., Kaymaz, Z., Reme, H., and Lucek, E. A.: Cluster observations of the magnetospheric low-latitude boundary layer and cusp during extreme solar wind and interplanetary magnetic field conditions: II. 7 November 2004 ICME and statistical survey, Solar Phys., 244, 233-261, 2007.

Burch, J. L., Reiff, P. H., Spiro, R. W., Heelis, R. A., and Fields, S. A.: Cusp region particle precipitation and ion convection for northward interplanetary magnetic field, Geophys. Res. Lett., 7, 393-396, 1980.

Chandler, M. O., Fuselier, S. A., Lockwood, M., and Moore, T. E.: Evidence of component merging equatorward of the cusp, J. Geophys. Res., 104, 22623-22634, 1999. 
Cowley, S. W. H.: Interpretation of observed relations between solar wind characteristics and effects at ionospheric altitudes, in: High-Latitude Plasma Physics, edited by: Hultqvist, B. and Hagfors, T., 225-249, 1983.

Cowley, S. W. H.: Magnetospheric and ionospheric low and the interplanetary magnetic field, in Physical basis of the Ionosphere in the Solar-Terrestrial System, AGARD CP-295, 401-414, 1981.

Cowley, S. W. H. and Lockwood, M.: Excitation and decay of solar wind-driven flows in the magnetosphere-ionosphere system, Ann. Geophys., 10, 103-115, 1992.

Davies, J. A., Yeoman, T. K., Rae, I. J., Milan, S. E., Lester, M., Lockwood, M., and McWilliams, A.: Ground-based observations of the auroral zone and polar cap ionospheric responses to dayside transient reconnection, Ann. Geophys., 20, 781-794, 2002, http://www.ann-geophys.net/20/781/2002/.

Davis, C. J. and Lockwood, M.: Predicted signatures of pulsed reconnection in ESR data, Ann. Geophys., 14, 1246-1256, 1996, http://www.ann-geophys.net/14/1246/1996/.

Dungey, J. W.: The structure of the exosphere of adventures in velocity space, in: Geophysics The Earth's Environment, edited by: DeWitt, C., Hieblot, J., and Lebeau, A., 505-550, 1963.

Dunlop, M. W., Woodward, T. I., Southwood, D. J., Glassmeier, K. H., and Elphic, R. C.: Merging 4 spacecraft data: comcepts used for analyzing discontinuities, Adv. Space Res., 20, 1101-1106, 1997.

Escoubet, C. P., Berchem, J., Bosqued, J. M., Trattner, K. J., Taylor, M., Pitout, F., Laakso, H., Masson, A., Dunlop, M., Dandouras, I., Reme, H., Fazakerley, A. N., and Daly, P.: Effect of a northward turning of the interplanetary magnetic field on cusp precipitation as observed by Cluster, J. Geophys. Res., 113, A07S13, doi:10.1029/2007JA012771, 2008.

Freeman, M. P., Farrugia, C. J., Burlaga, L. F., Hairston, M. R., and Greenspan, J. M.: The interaction of a magnetic cloud with the earth ionospheric convection in the Northern and Southern Hemispheres for a wide range of quasi-stready interplanetary magnetic field conditions, J. Geophys. Res., 98, 7633-7655, 1993.

Fuselier, S. A., Shelley, E. G., Peterson, W. K., Lennartsson, O. W., Collin, H. L., Drake, J. F., Ghielmetti, A. G., Balsiger, H., Burch, J. L., Johnstone, A., Rosenbauer, H., and Steinberg, J. T.: Bifurcated cusp ion signatures: Evidence for re-reconnection?, Geophys. Res. Lett., 24, 1471-1474, 1997.

Greenwald, R. A., Baker, K. B., Dudeney, J. R., Pinnock, M., Jones, T. B., Thomas, E. C., Villain, J. P., Cerisier, J. C., Senior, C., Hanuise, C., Hunsucker, R. D., Sofko, G., Koehler, J., Nielsen, E., Pellinen, R., Walker, A. D. M., Sato, N., and Yamagishi, H.: Darn Superdarn - a Global View of the Dynamics of HighLatitude Convection, Space Sci. Rev., 71, 761-796, 1995.

Hu, R., Bogdanova, Y. V., Owen, C. J., Foullon, C., Fazakerley, A. N., and Reme, H.: Cluster observations of the midaltitude cusp under strong northward interplanetary magnetic field, J. Geophys. Res., 113, A07S05, doi:10.1029/2007JA012726, 2008.

Imber, S. M., Milan, S. E., and Hubert, B.: Observations of significant flux closure by dual lobe reconnection, Ann. Geophys., 25, 1617-1627, 2007, http://www.ann-geophys.net/25/1617/2007/.

Johnstone, A. D., Alsop, C., Burge, S., Carter, P. J., Coates, A. J., Coker, A. J., Fazakerley, A. N., Grande, M., Gowen, R. A., Gurgiolo, C., Hancock, B. K., Narheim, B., Preece, A., Sheather, P. H., Winningham, J. D., and Woodliffe, R. D.: Peace: A plasma electron and current experiment, Space Sci. Rev., 79, 351-398,
1997.

Khan, H. and Cowley, S. W. H.: Observations of the response time of high-latitude ionospheric convection to variations in the interplanetary magnetic field using EISCAT and IMP-8 data, Ann. Geophys., 17, 1306-1335, 1999,

http://www.ann-geophys.net/17/1306/1999/.

Lavraud, B., Dunlop, M. W., Phan, T. D., Reme, H., Bosqued, J. M., Dandouras, I., Sauvaud, J. A., Lundin, R., Taylor, M., Cargill, P. J., Mazelle, C., Escoubet, C. P., Carlson, C. W., McFadden, J. P., Parks, G. K., Moebius, E., Kistler, L. M., Bavassano-Cattaneo, M. B., Korth, A., Klecker, B., and Balogh, A.: Cluster observations of the exterior cusp and its surrounding boundaries under northward IMF, Geophys. Res. Lett., 29, 56-1, doi:10.1029/2002GL015464, 2002.

Lavraud, B., Fedorov, A., Budnik, E., Grigoriev, A., Cargill, P. J., Dunlop, M. W., Rème, H., Dandouras, I., and Balogh, A.: Cluster survey of the high-altitude cusp properties: a three-year statistical study, Ann. Geophys., 22, 3009-3019, 2004a, http://www.ann-geophys.net/22/3009/2004/.

Lavraud, B., Fedorov, A., Budnik, E., Thomsen, M. F., Grigoriev, A., Cargill, P. J., Dunlop, M. W., Reme, H., Dandouras, I., and Balogh, A.: High-altitude cusp flow dependence on IMF orientation: A 3-year Cluster statistical study, J. Geophys. Res., 110, A02209, doi:10.1029/2004JA010804, 2005a.

Lavraud, B., Phan, T. D., Dunlop, M. W., Taylor, M. G. G. G. T., Cargill, P. J., Bosqued, J.-M., Dandouras, I., Rème, H., Sauvaud, J.-A., Escoubet, C. P., Balogh, A., and Fazakerley, A.: The exterior cusp and its boundary with the magnetosheath: Cluster multi-event analysis, Ann. Geophys., 22, 3039-3054, 2004b, http://www.ann-geophys.net/22/3039/2004/.

Lavraud, B., Reme, H., Dunlop, M. W., Bosqued, J. M., Dandouras, I., Sauvaud, J. A., Keiling, A., Phan, T. D., Lundin, R., Cargill, P J., Escoubet, C. P., Carlson, C. W., McFadden, J. P., Parks, G. K., Moebius, E., Kistler, L. M., Amata, E., Bavassano-Cattaneo, M. B., Korth, A., Klecker, B., and Balogh, A.: Cluster observes the high-altitude cusp region, Surv. Geophys., 26, 135-175, 2005 b.

Lockwood, M.: The location and characteristics of the reconnection X-line deduced from low-altitude satellite and ground-based observations: 1. Theory, J. Geophys. Res., 100, 21791-21802, 1995.

Lockwood, M., Davis, C. J., Onsager, T. G., and Scudder, J. D.: Modelling signatures of pulsed magnetopause reconnection in cusp ion dispersion signatures seen at middle altitudes, Geophys. Res. Lett., 25, 591-594, 1998.

Lockwood, M. and Moen, J.: Reconfiguration and closure of lobe flux by reconnection during northward IMF: possible evidence for signatures in cusp/cleft auroral emissions, Ann. Geophys., 17, 996-1011, 1999, http://www.ann-geophys.net/17/996/1999/.

Lockwood, M., Moen, J., van Eyken, A. P., Davies, J. A., Oksavik, K., and McCrea, I. W.: Motion of the dayside polar cap boundary during substorm cycles: I. Observations of pulses in the magnetopause reconnection rate, Ann. Geophys., 23, 3495-3511, 2005, http://www.ann-geophys.net/23/3495/2005/.

Maezawa, K.: Magnetosphere convection induced by the positive and negative $\mathrm{Z}$ omponents of the interplanetary magnetic field equantitative analysis using polar cap magnetic records, J. Geophys. Res., 81, 2289-2303, 1976.

Maynard, N. C., Burke, W. J., Pfaff, R. F., Weber, E. J., Ober, D. M., 
Weimer, D. R., Moen, J., Milan, S., Maseide, K., Sandholt, P. E., Egeland, A., Soraas, F., Lepping, R., Bounds, S., Acuna, M. H., Freudenreich, H., Machuzak, J. S., Gentile, L. C., Clemmons, J. H., Lester, M., Ning, P., Hardy, D. A., Holtet, J. A., Stadsnes, J., and van Eyken, T.: Driving dayside convection with northward IMF: Observations by a sounding rocket launched from Svalbard, J. Geophys. Res., 105, 5245-5263, 2000.

McCrea, I. W., Lockwood, M., Moen, J., Pitout, F., Eglitis, P., Aylward, A. D., Cerisier, J.-C., Thorolfssen, A., and Milan, S. E.: ESR and EISCAT observations of the response of the cusp and cleft to IMF orientation changes, Ann. Geophys., 18, 1009-1026, 2000, http://www.ann-geophys.net/18/1009/2000/.

Milan, S. E., Lester, M., Cowley, S. W. H., and Brittnacher, M.: Dayside convection and auroral morphology during an interval of northward interplanetary magnetic field, Ann. Geophys., 18, 436-444, 2000, http://www.ann-geophys.net/18/436/2000/.

Newell, P. T. and Meng, C. I.: The cusp and the cleft/boundary layer - Low-altitude identification and statistical local time variation, J. Geophys. Res., 93, 14549-14556, 1988.

Newell, P. T., Meng, C. I., Sibeck, D., and Lepping, R.: Some low altitude cusp dependencies on the interplanetary magnetic field, J. Geophys. Res., 94, 8921-8927, 1989.

Onsager, T. G. and Fuselier, S. A.: The location of the magnetopause reconnection for northward and southward interplanetary magnetic field, Solar System plasmas in space and time, Geophys. Monogr. Ser., edited by: Burch, J. L. and Waite Jr., J. H., Am. Geophys. Union, Washington, D.C., 84, 183-197, 1994.

Phan, T. D., Oieroset, M., and Fujimoto, M.: Reconnection at the dayside low-latitude magnetopause and its nonrole in low-latitude boundary layer formation during northward interplanetary magnetic field, Geophys. Res. Lett., 32, L17101, doi:10.1029/2005GL023355, 2005.

Phan, T. D. and Paschmann, G.: Low-latitude dayside magnetopause and boundary layer for high magnetic shear .1. Structure and motion, J. Geophys. Res.-Space Phys., 101, 7801-7815, 1996.

Pitout, F., Bosqued, J.-M., Alcayd, D., Denig, W. F., and Rème, H.: Observations of the cusp region under northward IMF, Ann. Geophys., 19, 1641-1653, 2001, http://www.ann-geophys.net/19/1641/2001/.

Pitout, F., Escoubet, C. P., Bogdanova, Y. V., Georgescu, E., Fazakerley, A. N., and Reme, H.: Response of the mid-altitude cusp to rapid rotations of the IMF, Geophys. Res. Lett., 33, L11107, doi:10.1029/2005GL025460, 2006a.

Pitout, F., Escoubet, C. P., Klecker, B., and Rème, H.: Cluster survey of the mid-altitude cusp: 1. size, location, and dynamics, Ann. Geophys., 24, 3011-3026, 2006b, http://www.ann-geophys.net/24/3011/2006/.

Pitout, F., Newell, P. T., and Buchert, S. C.: Simultaneous high- and low-latitude reconnection: ESR and DMSP observations, Ann. Geophys., 20, 1311-1320, 2002,

http://www.ann-geophys.net/20/1311/2002/.

Pryse, S. E., Sims, R. W., Moen, J., and Oksavik, K.: Ionospheric signatures of the low-latitude boundary layer under conditions of northward IMF and small clock angle, Ann. Geophys., 24, 21692178, 2006, http://www.ann-geophys.net/24/2169/2006/.

Pryse, S. E., Smith, A. M., and Kersley, L.: Dayside ionospheric response to changes in IMF polarity: optical and plasma-flow observations, Ann. Geophys., 18, 782-788, 2000a, http://www.ann-geophys.net/18/782/2000/.

Pryse, S. E., Smith, A. M., Kersley, L., Walker, I. K., Mitchell, C. N., Moen, J., and Smith, R. W.: Multi-instrument probing of the polar ionosphere under steady northward IMF, Ann. Geophys., 18, 90-98, 2000b,

http://www.ann-geophys.net/18/90/2000/.

Pryse, S. E., Smith, A. M., Walker, I. K., and Kersley, L.: Multiinstrument study of footprints of magnetopause reconnection in the summer ionosphere, Ann. Geophys., 18, 1118-1127, 2000c, http://www.ann-geophys.net/18/1118/2000/.

Reiff, P. H., Spiro, R. W., and Burch, J. L.: Cusp proton signatures and the interplanetary magnetic field, J. Geophys. Res., 85, 5997-6005, 1980.

Rème, H., Aoustin, C., Bosqued, J. M., Dandouras, I., Lavraud, B., Sauvaud, J. A., Barthe, A., Bouyssou, J., Camus, Th., CoeurJoly, O., Cros, A., Cuvilo, J., Ducay, F., Garbarowitz, Y., Medale, J. L., Penou, E., Perrier, H., Romefort, D., Rouzaud, J., Vallat, C., Alcaydé, D., Jacquey, C., Mazelle, C., d’Uston, C., Möbius, E., Kistler, L. M., Crocker, K., Granoff, M., Mouikis, C., Popecki, M., Vosbury, M., Klecker, B., Hovestadt, D., Kucharek, H., Kuenneth, E., Paschmann, G., Scholer, M., Sckopke, N., Seidenschwang, E., Carlson, C. W., Curtis, D. W., Ingraham, C., Lin, R. P., McFadden, J. P., Parks, G. K., Phan, T., Formisano, V., Amata, E., Bavassano-Cattaneo, M. B., Baldetti, P., Bruno, R., Chionchio, G., Di Lellis, A., Marcucci, M. F., Pallocchia, G., Korth, A., Daly, P. W., Graeve, B., Rosenbauer, H., Vasyliunas, V., McCarthy, M., Wilber, M., Eliasson, L., Lundin, R., Olsen, S., Shelley, E. G., Fuselier, S., Ghielmetti, A. G., Lennartsson, W., Escoubet, C. P., Balsiger, H., Friedel, R., Cao, J.-B., Kovrazhkin, R. A., Papamastorakis, I., Pellat, R., Scudder, J., and Sonnerup, B.: First multispacecraft ion measurements in and near the Earths magnetosphere with the identical Cluster ion spectrometry (CIS) experiment, Ann. Geophys., 19, 1303-1354, 2001,

http://www.ann-geophys.net/19/1303/2001/.

Russell, C. T.: The configuration of the magnetosphere, Critical Problems of Magnetospheric Physics, edited by: Dyer, E. R., p.1, Natinal Academy of Sciences, Washington, 1972.

Scurry, L., Russell, C. T., and Gosling, J. T.: Geomagnetic-Activity and the Beta-Dependence of the Dayside Reconnection Rate, J. Geophys. Res.,, 99, 14811-14814, 1994a.

Scurry, L., Russell, C. T., and Gosling, J. T.: A Statistical Study of Accelerated Flow Events at the Dayside Magnetopause, J. Geophys. Res., 99, 14815-14829, 1994b.

Sonnerup, B. U. and Cahill, L. J.: Magnetopause Structure and Attitude from Explorer 12 Observations, J. Geophys. Res.,, 72, 171183, 1967.

Tsyganenko, N. A.: Modeling the Earths Magnetospheric Magnetic-Field Confined within a Realistic Magnetopause, J. Geophys. Res., 100, 5599-5612, 1995.

Wilken, B., Daly, P. W., Mall, U., Aarsnes, K., Baker, D. N., Belian, R. D., Blake, J. B., Borg, H., Bchner, J., Carter, M., Fennell, J. F., Friedel, R., Fritz, T. A., Gliem, F., Grande, M., Kecskemety, K., Kettmann, G., Korth, A., Livi, S., McKenna-Lawlor, S., Mursula, K., Nikutowski, B., Perry, C. H., Pu, Z. Y., Roeder, J., Reeves, G. D., Sarris, E. T., Sandahl, I., Sraas, F., Woch, J., and Zong, Q.-G.: First results from the RAPID imaging energetic particle spectrometer on board Cluster, Ann. Geophys., 19, 1355-1366, 2001, http://www.ann-geophys.net/19/1355/2001/.

Wing, S., Newell, P. T., and Ruohoniemi, J. M.: Double cusp: 
Model Predication and observation verification, J. Geophys. Res., 106, 25571-25594, 2001.

Woch, J. and Lundin, R.: Magnetosheath plasma precipitation in the polar cusp and its control by the interplanetary magnetic field, J. Geophys. Res.-Space Phys., 97, 1421-1430, 1992.

Woodfield, E. E., Davies, J. A., Eglitis, P., and Lester, M.: A case study of HF radar spectral width in the post midnight magnetic local time sector and its relationship to the polar cap boundary, Ann. Geophys., 20, 501-509, 2002a, http://www.ann-geophys.net/20/501/2002/.

Woodfield, E. E., Davies, J. A., Lester, M., Yeoman, T. K., Eglitis, P., and Lockwood, M.: Nightside studies of coherent HF Radar spectral width behaviour, Ann. Geophys., 20, 1399-1413, 2002b, http://www.ann-geophys.net/20/1399/2002/.

Woodfield, E. E., Hosokawa, K., Milan, S. E., Sato, N., and Lester, M.: An inter-hemispheric, statistical study of nightside spectral width distributions from coherent HF scatter radars, Ann. Geophys., 20, 1921-1934, 2002c,

http://www.ann-geophys.net/20/1921/2002/.
Yeoman, T. K., Hanlon, P. G., and McWilliams, K. A.: Letter to the Editor A statistical study of the location and motion of the HF radar cusp, Ann. Geophys., 20, 275-280, 2002, http://www.ann-geophys.net/20/275/2002/.

Zong, Q. G., Fritz, T. A., Zhang, H., Korth, A., Daly, P. W., Dunlop, M. W., Glassmeier, K. H., Reme, H., and Balogh, A.: Triple cusps observed by Cluster - Temporal or spatial effect?, Geophys. Res. Lett., 31, L09810, doi:10.1029/2003GL019128, 2004.

Zong, Q. G., Zhang, H., Fritz, T. A., Goldstein, M. L., Wing, S., Keith, W., Winningham, J. D., Frahm, R., Dunlop, M. W., Korth, A., Daly, P. W., Reme, H., Balogh, A., and Fazakerley, A. N.: Multiple cusps during an extended northward IMF period with a significant B-y component, J. Geophys. Res., 113, A01210, doi:10.1029/2006JA012188, 2008. 